\title{
Papers
}

\section{Extent of apoptosis in ovarian serous carcinoma: relation to mitotic and proliferative indices, p53 expression, and survival}

\author{
Máirín E Mc Menamin, Amanda J O’Neill, Eoin F Gaffney
}

\begin{abstract}
Aims-To assess the extent of apoptosis in ovarian serous carcinoma and to examine possible relations between apoptosis, cell proliferation, p53 overexpression, and patient survival.

Methods-Apoptotic and mitotic indices were obtained by examining haematoxylin and eosin stained sections from 30 patients with ovarian serous carcinoma. Apoptosis was also evaluated semiquantitatively by in situ end labelling of fragmented DNA. Expression of p53 and determination of Ki-67 labelling indices were based on immunohistochemical staining. Clinical details were obtained from patients' clinical records. For statistical analysis, Fisher's exact test, parametric (Pearson) linear correlations, and the Kaplan-Meier method were used.
\end{abstract}

Results-The mean apoptotic index was $1.3 \%$ (range $0.02-3.9 \%$ ), the mean mitotic index was $0.4 \%$ (range $0.02-1.1 \%$ ), and the mean Ki-67 labelling index was $16 \%$ (range 4-32\%). There were significant correlations between the apoptotic and mitotic indices $(p<0.0205)$ and between the mitotic and Ki-67 labelling indices $(p<0.024)$. There was a significant correlation between a high apoptotic index and poor prognosis $(p<0.02)$. p53 was overexpressed in 16 cases but the extent of apoptosis and outcome were both independent of 53 status.

Conclusions-These results suggest that regulation of apoptosis is an integral component of tumour cell kinetics in ovarian serous carcinoma, and that increased apoptosis is indicative of aggressive tumour growth. p53 expression did not correlate with altered apoptosis, but the possibility of an attenuated apoptotic response to subsequent DNA damage by anticancer agents is not excluded. (f Clin Pathol: Mol Pathol 1997;50:242-246)

Keywords: apoptosis; mitosis; cell proliferation; p53; ovarian serous carcinoma
Apoptosis is the highly conserved, genetically of mediated process of selective cell deletion that is occurs in embryogenesis, normal tissue home- $\hat{N}$ ostasis, and in many human diseases. ${ }^{12}$ Apop- 을 tosis is fundamental in tumour cell kinetics, ${ }^{1}$ and susceptibility to apoptosis in untreated malignant tumours varies with tumour type. ${ }^{3} \frac{}{0}$ The precise mechanisms that regulate tumour $\mathbb{\Phi}$ cell apoptosis in vivo are not understood fully $\vec{\theta}$ but there are numerous endogenous and exogenous initiating factors including growth factor deprivation, viral infection, irradiation, and cytotoxic chemotherapy. ${ }^{14}$ In addition, apoptosis is subject to modulation by a large number of proto-oncogenes and tumour suppressor $\frac{O}{\mathbb{D}}$ genes including c-myc, bcl-2, and p53.1 ${ }^{15}$

Ovarian cancer is the leading cause of death in industrial countries among women with carcinomas of reproductive organs. ${ }^{6}$ Most patients present with advanced disease, management of which consists of debulking surgery followed by chemotherapy. ${ }^{6-8}$ The principal prognostic $\frac{0}{3}$ factors are patient age, stage of disease, residual disease after surgical resection, and histological $\mathrm{O}$ grade. ${ }^{8-11}$ Multiple genetic changes, including allele $\operatorname{loss}^{12-14}$ and oncogene and tumour suppressor gene abnormalities ${ }^{15-22}$ have been $\frac{D}{O}$ described in ovarian carcinoma, particularly in serous carcinoma. p53 gene mutations and ${ }^{N}$ abnormal stabilisation of the $\mathrm{p} 53$ protein have $N$ been reported to correlate with late clinical N stage, high grade, and presence of residual dis- $O$ ease in serous carcinoma. ${ }^{19-22}$ Recently, it has been suggested that p53 mutations are associ- $\frac{\mathscr{D}}{\mathscr{N}}$ ated with reduced susceptibility to chemotherapy induced apoptosis. ${ }^{22}$

We examined the extent of apoptosis in ovarian serous carcinoma in relation to mitotic $\stackrel{D}{\Omega}$ and proliferative indices, abnormal p53 expres- $\stackrel{\square}{\square}$ sion, and survival.

\section{Materials and methods}

All cases diagnosed as ovarian serous carcinoma during 1990-95 were retrieved from the files of the department of histopathology, St James's Hospital, Dublin. Material consisted of formalin fixed, paraffin wax embedded sections of biopsy or resection specimens. Following review and the inclusion of additional material from the Coombe Lying-In Hospital, Dublin, 


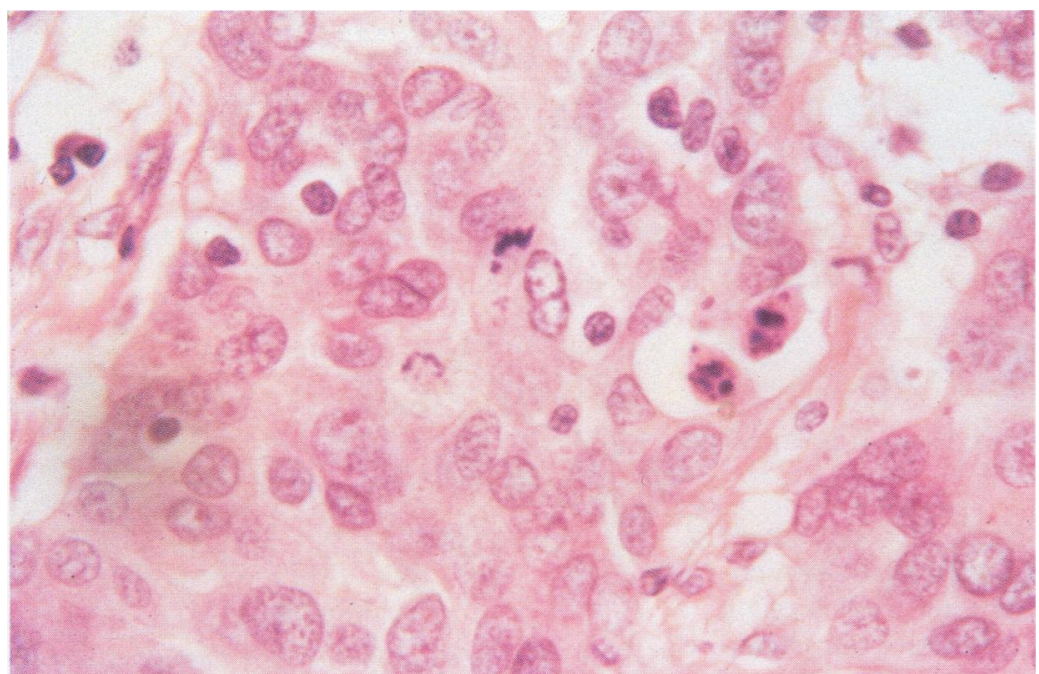

Figure 1 Apoptotic tumour cells (right of centre) in ovarian serous carcinoma.

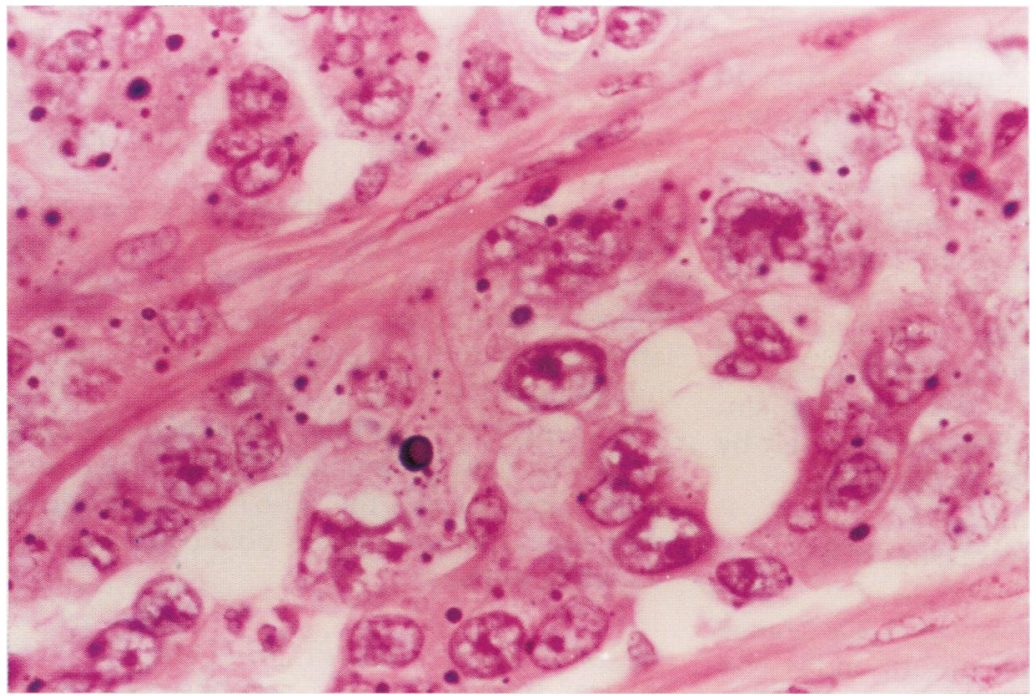

Figure 2 Multiple intracytoplasmic basophilic inclusions simulating numerous apoptotic bodies seen in one case.

30 cases of ovarian serous carcinoma formed the basis of this study. Two specimens were available from two patients, each of whom had biopsies taken before and after chemotherapy. All other specimens were from untreated patients. Each tumour was assigned a pathological grade.

One or two haematoxylin and eosin stained sections were selected for evaluation of apoptosis, mitoses, and immunostaining. The apoptotic and mitotic indices were assessed as described previously. ${ }^{3}$ Briefly, the number of apoptotic tumour cells and mitoses in 10 high power $(\times 40)$ fields (defined by a $1 \mathrm{~mm}$ index 100 square grid) was expressed as a percentage of the total number of tumour cells in these 10 fields. The edges of necrotic zones were avoided as were areas containing a high proportion of stromal cells.

Immunohistochemical staining for p53 and $\mathrm{Ki}-67$ was performed using microwave induced antigen retrieval and a standard avidin-biotin complex method, using appropriate controls. ${ }^{23}$ Sections were incubated in monoclonal mouse anti-p53-DO7 (Novacastra, Newcastle upon Tyne, UK; $1 / 50$ dilution), overnight at $4^{\circ} \mathrm{C}$, and monoclonal rabbit anti-Ki-67 (Dako, High
Wycombe, Bucks, UK; 1/80 dilution), at room temperature for one hour. The colour reaction product was obtained with diaminobenzidine (seven minutes) and a light haematoxylin counterstain. The p53 immunoreactivity was graded initially on a scale of $0-3(0$, all tumour cells negative; $1,<1 \%$ (weakly) positive tumour cells; 2, multifocal aggregates of uniformly staining tumour cells; 3 , diffuse positive staining throughout the tumour). Subsequently, grades 0 and 1 were considered to be p53 negative, and tumours graded as 2 or 3 were considered to be $\mathrm{p} 53$ positive. ${ }^{23}$ Cell proliferation was assessed by the $\mathrm{Ki}-67$ labelling index, the percentage of $\mathrm{Ki}-67$ positive cells within the grid boundaries of 10 non-selected $\times 40$ objective fields.

In situ end labelling was performed using an apoptosis detection kit (Apoptag; Oncor Inc, Gaithersburg, Missouri, USA). The principle of in situ end labelling is that terminal deoxynucleotidyl transferase (TdT) catalyses the binding of digoxygenin-dUTP to the 3'-OH ends of fragmented DNA in apoptotic cells. ${ }^{24}$ Using antidigoxygenin peroxidase, and a methyl green counterstain, a brown colour reaction product identifies apoptotic nuclei. In situ end labelling was assessed semiquantitatively, using a five tiered scale. ${ }^{24}$

Clinical details and follow up were obtained from hospital charts and patients' general practitioners. Survival was calculated from the date of surgery until death or the last date seen alive by the patient's doctor. From raw data entered in $2 \times 2$ contingency tables or in columns (Instat, Graphpad Software, San Diego, California, USA), p values were obtained using Fischer's exact test and parametric (Pearson) linear correlations. Survival was investigated as a function of the apoptotic and mitotic indices and p53 using Cox's proportionate hazard regression, allowing for censoring. Survival curves were displayed by means of a Kaplan-Meier plot. The group difference was tested by the log rank test.

\section{Results}

CLINICAL DATA, STAGE, AND GRADE

The mean patient age was 57 years (range 27-81 years). There were 3 stage 1,1 stage 2 , 20 stage 3 , and 6 stage 4 carcinomas. Pathological grades were: grade 1 (3), grade 2 (9), and grade 3 (18). Survival data was available for 29 patients: 12 were alive and 17 were dead. Follow up intervals ranged from one to 62 months (mean 18.2 months).

\section{ASSESSMENT OF APOPTOSIS (GENERAL)}

Apoptotic tumour cells and apoptotic bodies were scattered among viable tumour cells (fig 1). The degree of apoptotic and mitotic activity showed considerable variation from field to field in grade 2 and grade 3 tumours, but this was accounted for by the assessment of 10 random high power fields. The number of tumour cells in a grid area varied with cell size and architectural pattern, and the mean number of tumour cells counted per case was 5524 (range 2190-10 662). An abundance of intracytoplasmic basophilic granules in one case simulated 


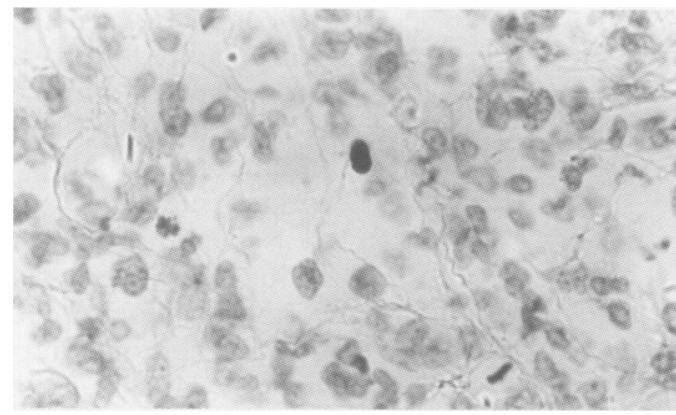

Figure 3 One apoptotic tumour cell (centre) is highlighted by the in situ end labelling technique.

very extensive apoptosis (fig 2). However, these basophilic inclusions had focal calcific laminations like miniature psammoma bodies using the von Kossa stain and a distinctive ultrastructural appearance which differed from that of apoptotic bodies.

APOPTOSIS (IN SITU END LABELLING)

Apoptotic tumour cells identified by in situ end labelling were scattered in a similar distribution but were better highlighted than in haematoxylin and eosin sections (fig 3). There was a general correlation between semiquantitative assessments made on in situ end labelling and haematoxylin and eosin sections. Frequently, however, apoptotic bodies were unstained, although morphologically recognisable, as noted previously. ${ }^{24}$ In a few specimens, in situ end labelling staining was affected adversely by suboptimal fixation and tissue processing.

\section{APOPTOTIC, MITOTIC, AND PROLIFERATIVE}

INDICES

The mean apoptotic index was $1.3 \%$ (range $0.02-3.9 \%$ ) and the mean mitotic index was $0.4 \%$ (range $0.02-1.1 \%$ ). Higher apoptotic indices were associated with grade 2 and grade 3 tumours: the mean apoptotic index in each grade was $0.6 \%$ (grade 1 ), $1.1 \%$ (grade 2 ), and $2.04 \%$ (grade 3 ). This was not statistically significant largely because of the variability of the apoptotic index in higher grade tumours. Moreover, there was no correlation between the mitotic index and grade. The lack of correlation between tumour grade and the apoptotic and mitotic indices might be due, in part, to the

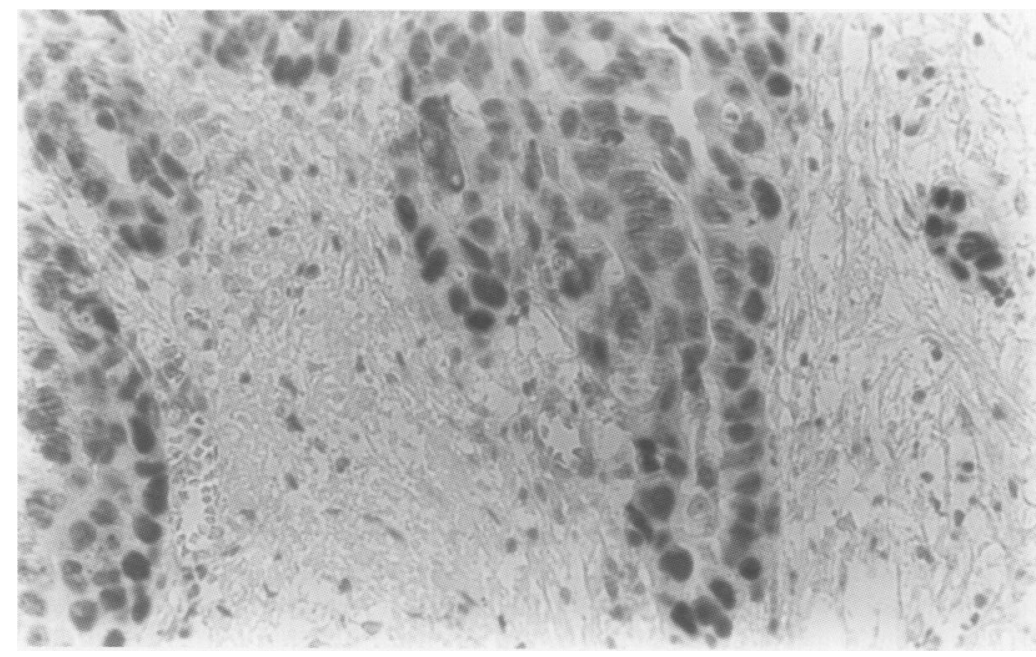

Figure 4 An ovarian serous carcinoma demonstrating positive immunostaining for p53.

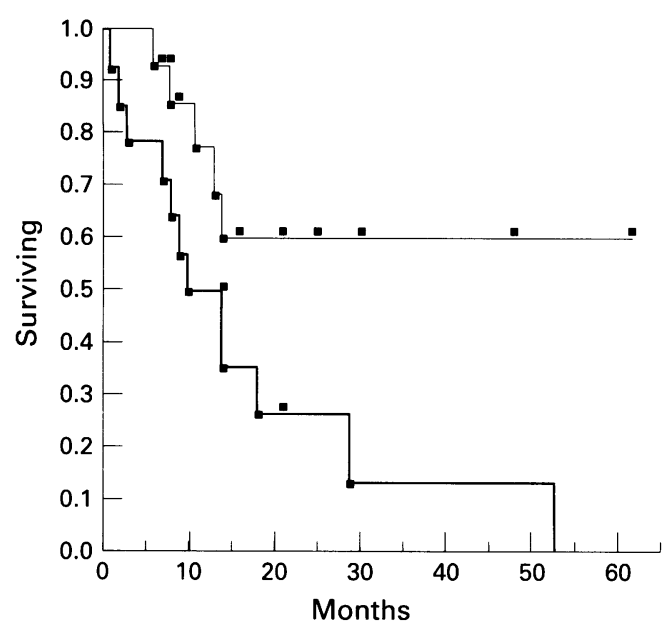

Figure 5 Kaplan-Meier survival plot: survival associated with an apoptotic index $<1.3 \%$ (upper curve) is significantly better than that associated with an apoptotic index $\geqslant 1.3 \%$ (lower curve) $(p<0.02)$.

relatively small number of cases analysed. However, there was a close linear correlation between the apoptotic and mitotic indices $(r=0.4210 ; \mathrm{p}<0.0205)$.

The mean Ki-67 labelling index was $16 \%$ (range 4-32\%). There was no correlation between the apoptotic and $\mathrm{Ki}-67$ labelling indices, but there was a significant linear corre- $\vec{\oplus}$ lation between the mitotic and $\mathrm{Ki}-67$ labelling indices $(r=0.4114 ; \mathrm{p}<0.0239)$.

In both cases where postchemotherapy specimens were examined, the apoptotic and mitotic indices and the $\mathrm{Ki}-67$ labelling index were similar to the indices obtained from the original specimens.

IMMUNOHISTOCHEMICAL STAINING FOR P53

Nuclear staining for p53 was observed in 16 cases. Staining intensity was variable and was often maximal in peripheral tumour cells (fig 4). No cytoplasmic immunoreactivity was seen. Apoptotic tumour cells were distributed in a 8 similar pattern in $\mathrm{p} 53$ positive and $\mathrm{p} 53$ negative tumours. There was no correlation between $ᄋ$ p53 overexpression or grade of p53 immunoreactivity and the apoptotic, mitotic or $\mathrm{Ki}-67$ 을 labelling indices.

CLINICOPATHOLOGICAL CORRELATIONS

The extent of apoptosis correlated with survival time (median survival, 14 months). A cut off point of apoptotic index $<1.3 \%$ was selected subsequently for display of KaplanMeier survival curves (fig 5). The difference in 7 survival between the low and high apoptotic index groups (log rank test, $\chi^{2}$ ) was statistically significant $(p<0.02)$. In contrast, there was no correlation between the mitotic index, the $\mathrm{Ki}-67$ labelling index, or p53 overexpression, and survival.

\section{Discussion}

Apoptosis in human tumours may be inconspicuous or extensive, depending on tumour type. ${ }^{32325}$ We found a moderate amount of apoptosis in ovarian serous carcinoma: apoptotic indices (mean $1.3 \%$ ) were comparable to those of adenocarcinoma of the lung and 
certain other common cancers. ${ }^{323}$ As reported previously, ${ }^{36}$ apoptosis was identified readily and measured by light microscopy using standard haematoxylin and eosin sections. Early apoptotic nuclear changes not identified reliably by routine light microscopy were detected by in situ end labelling, a technique that identifies fragmented apoptotic cell DNA. ${ }^{24}$ In general, our semiquantitative apoptosis assessments based on haematoxylin and eosin and in situ end labelling sections were comparable and the apoptotic index range was similar to that reported by Diebold et al, ${ }^{28}$ who used an end labelling technique only. The limitations of end labelling techniques have been discussed fully elsewhere. ${ }^{24} 27{ }^{29}$ Haematoxylin and eosin sections were required for the purpose of this study, in order to measure apoptosis and mitoses in the same tumour fields.

Our results indicate that there are close links between apoptosis and cell proliferation in ovarian serous carcinoma. We found a significant linear correlation between the apoptotic and mitotic indices, as reported recently in certain other tumour types. ${ }^{23}{ }^{31-35}$ The Ki-67 labelling index, a measure of the percentage of proliferating cells, correlated significantly with the mitotic index. Furthermore, we observed that a high apoptotic index correlated very significantly with a poor prognosis in ovarian serous carcinoma. These findings suggest strongly that: regulation of apoptosis is an integral component of tumour cell kinetics, as in normal tissue homeostasis; and in certain tumour types, increased apoptosis is at least as significant as increased mitotic activity in reflecting aggressive tumour growth. Tumour growth is determined by the percentage of proliferating cells, cell cycle time, and the amount of cell loss. ${ }^{36}$ It has been suggested that apoptosis is in some way "defective" or inhibited in cancer. ${ }^{26}$ 36-38 Data reported herein and elsewhere do not support the universal applicability of this concept: untreated carcinomas appear to display more, not less, apoptosis than normal tissues. ${ }^{23}$ 33-35 However, we cannot exclude the possibility that in tumours showing increasing genomic instability affecting specific cell cycle regulatory genes, the tightly controlled process of apoptosis might become deregulated.

The p53 phosphoprotein is a transcription factor that controls numerous cellular genes, including those involved in regulation of the cell cycle. ${ }^{39}$ The p53 protein also induces growth arrest or apoptosis following DNA damage. In this study of ovarian serous carcinoma, the extent and distribution of apoptosis was independent of p53 overexpression, and p53 was not of prognostic significance. Ovarian carcinomas with p 53 mutations are less susceptible to chemotherapy induced apoptosis, possibly because of an inability to transactivate the apoptosis inducing gene bax. ${ }^{40}$ However, the role of $\mathrm{p} 53$ in regulating the extent of tumour cell apoptosis in vivo is not clear. ${ }^{41}$ Different p53 mutants have different biological effects. ${ }^{39}$ Even if all p53 mutant proteins were associated with diminished apoptosis inducing functions, $\mathrm{p} 53$ might not be required for fine tuning apoptosis in all untreated human tumours. With regard to the present study, it is accepted that immunostaining for p53 is not as specific as polymerase chain reaction-single strand conformational polymorphism analysis as a screening technique for p53 mutations, although there is good concordance. ${ }^{19}$ We cannot exclude the possibility that abnormal stabilisation of wildtype $\mathrm{p} 53$ protein in a minority of our $\mathrm{p} 53$ positive cases may have been associated with a higher apoptotic index. However, we are satisfied that even if this were so, the scatter of apoptotic indices in this series of ovarian serous carcinoma indicates that p53 abnormalities were not associated with alterations in the extent of apoptosis. In support of this, recent work on non-small cell lung carcinoma and leiomyosarcoma suggests that mutations in the "hot spot region" of p53 are not associated with attenuated apoptosis (O'Neill, Staunton, McMahon, Gaffney, unpublished data, 1997). The likely significance of p53 mutations in spontaneous human tumours is that the apoptosis response to subsequent DNA damage due to chemotherapy or radiation therapy might be reduced, as the experimental evidence suggests.

Does susceptibility to apoptosis in vivo predict an apoptotic response to radiation therapy or chemotherapy? Levine et al ${ }^{31}$ reported that a low apoptotic index in cervical carcinoma correlated with radiosensitivity and a favourable prognosis. However, there is no in vivo evidence that the apoptotic index might be useful for predicting clinical responses to chemotherapy (or chemoresistance) in ovarian serous carcinoma or other malignancies. Leukaemias, germ cell tumours, and small cell undifferentiated carcinomas-all chemosensitive malignancies - have low, intermediate, and high apoptotic indices, respectively. ${ }^{3}$ Furthermore, anticancer agents induce apoptosis by several different mechanisms, ${ }^{43}{ }^{44}$ and mechanisms of chemoresistance, including those associated with bcl-2 overexpression or p53 mutation, ${ }^{40}{ }^{45}$ are further complicated by intratumour heterogeneity. We consider it likely that susceptibility to apoptosis and chemosensitivity in tumours represent independent variables, but this clinically relevant topic merits more detailed investigation.

We acknowledge the help of Dr Noreen Gleeson (Departmen of Obstetrics and Gynaecology). Dr Alan Kelly (Trinity College, Dublin) carried out statistical analyses. Amanda O'Neill is supported by the Irish Association for Cancer Research and CRAB (Irish Cancer Society).

1 Wyllie AH. Apoptosis and the regulation of cell numbers in normal and neoplastic tissues: an overview. Cancer Metast Rev 1992;11:95-103.

2 Solary E, Dubrez L, Eymin B. The role of apoptosis in the pathogenesis and treatment of diseases. Eur Respir F 1996; 9:1293-305.

3 Staunton MJ, Gaffney EF. Tumour type is a determinant of susceptibility to apoptosis. Am F Clin Pathol 1995;103:3007.

4 Kerr JFR, Winterford CM, Harmon BV. Apoptosis. Its significance in cancer and cancer therapy. Cancer 1994;73: 2013-6.

5 Hoffman B, Liebermann DA. Molecular controls of apoptosis: differentiation/growth arrest primary response genes, proto-oncogenes, and tumour suppressor genes as positive and negative modulators. Oncogene 1994;9:180712 . 
6 Cannistra SA. Cancer of the ovary. N Engl f Med 1993;329

7 McGuire WP, Hoskins WJ, Brady MF, Kucera PR, Partridge EE, Look KY, et al. Cyclophosphamide and cisplatin compared with paclitaxel and cisplatin in patient with stage III and stage IV ovarian cancer. $N$ Engl $\mathcal{f} \mathrm{Med}$ 1996;334: 1-6.

8 Partridge EE, Phillips JL, Menck HR. The National Cancer Data Base report on ovarian cancer treatment in United States hospitals. Cancer 1996;78:2236-46.

9 Swenerton KD, Hislop TG, Spinelli J, LeRiche JC, Yang N, Boyes DA. Ovarian carcinoma: a multivariate analysis of prognostic factors. Obstet Gynecol 1985;65:264-9.

10 Ozols RF, Garvin AJ, Costa J, Simon RM, Young RC. Advanced ovarian cancer. Correlation of histologic grade with response to therapy and survival. Cancer 1980;45:572 81 .

11 Sorbe B, Frankendal BO, Veress B. Importance of histologic grading in the prognosis of epithelial ovarian carcinoma. Obstet Gynecol 1982;59:576-82.

12 Eccles DM, Brett L, Lessells A, Gruber L, Lane D, Steel $\mathrm{CM}$, et al. Overexpression of the p53 protein and allele loss at $17 \mathrm{p} 13$ in ovarian carcinoma. Br $\mathcal{F}$ Cancer 1992;65:40-4

13 Foulkes WD, Ragoussis J, Stamp GWH, Allan GJ, Trowsdale J. Frequent loss of heterozygosity on chromosome 6 in human ovarian carcinoma. Br f Cancer 1993;67: $551-9$.

14 Kiechle-Schwarz M, Bauknecht T, Wienker T, Walz L, Pfleiderer A. Loss of constitutional heterozygosity on chromosome $11 \mathrm{p}$ in human ovarian cancer. Cancer 1993;72. 2423-32.

15 Van Dam PA, Vergote IB, Lowe DG, Watson JV, Van Damme P, Van der Auwera J-C, et al. Expression of c-erbB-2, c-myc, and c-ras oncoproteins, insulin-like growth factor receptor in ovarian carcinoma. 7 Clin Pathol growth factor recept

16 Tashiro H, Miyazaki K, Okamura H, Iwai A, Fukumoto M c-myc overexpression in human primary ovarian tumours: its relevance to tumour progression. Int $\mathcal{F}$ Cancer 1992;50 $828-33$.

17 Herod JJO, Eliopoulos AG, Warwick J, Niedobitek G, Young LS, Kerr DJ. The prognostic significance of bcl-2 and p5 expression in ovarian carcinoma. Cancer Res 1996;56: 2178-84.

18 Henriksen R, Wilander E, Öberg K. Expression and prognostic significance of bcl-2 in ovarian tumours. $\mathrm{Br}$ prognostic significance

19 Mc Manus DT, Yap EPH, Maxwell P, Russell SEH, Toner PG, McGee JO'D. p53 expression, mutation and allelic deletion in ovarian cancer. $\mathcal{F}$ Pathol 1994;174:159-68.

20 Mc Manus DT, Murphy M, Arthur K, Hamilton PW, Russell SEH, Toner PG. p53 mutation, allele loss on chromosome $17 \mathrm{p}$, and DNA content in ovarian carcinoma. $\mathcal{F}$ Patho 1996;179:177-82.

21 Levesque MA, Katsaros D, Yu H, Zola P, Sismondi P, Giardina $G$, et al. Mutant $\mathrm{p} 53$ protein overexpression is associated with poor outcome in patients with well or moderately ated with poor outcome in patients with well or moderately differen

22 Klemi P-J, Pylkkänen L, Kiilholma P, Kurvinen K, Joensuu H. p53 protein detected by immunohistochemistry as a prognostic factor in patients with epithelial ovarian carcinoma. Cancer 1995;76:1201-8.

23 O'Neill AJ, Staunton MJ, Gaffney EF. Apoptosis occurs independently of bcl-2 and p53 overexpression in nonsmall cell lung carcinoma. Histopathology 1996;29:45-50.

24 Gaffney EF, O'Neill AJ, Staunton MJ. In situ end-labelling light microscopic assessment and ultrastructure of apoptolight microscopic assessment and ultrastructure of apopt
sis in lung carcinoma. 7 Clin Pathol 1995;48:1017-21.

25 Meyn RE, Stephens LC, Ang KK, Hunter NR, Brock WA Milas L, et al. Heterogeneity in the development of apopto- sis in irradiated murine tumours of different histologies. Int f Radiat Biol 1993;64:583-91.

26 Hollowood K, Macartney JC. Reduced apoptotic cell death in follicular lymphoma. $\mathcal{F}$ Pathol 1991;163:337-42.

27 Ansari B, Coates PJ, Greenstein BD, Hall PA. In situ end-labelling detects DNA strand breaks in apoptosis and other physiological and pathological states. 7 Pathol 1993; 170:1-8.

28 Diebold J, Baretton G, Felchner M, Meier W, Dopfer K, Schmidt $\mathrm{M}$, et al. bcl-2 expression, p53 accumulation, and apoptosis in ovarian carcinomas. Am $\mathcal{f}$ Clin Pathol

29 Sasano H. In situ end-labelling and its applications to the study of endocrine disease: how can we study programmed cell death in surgical pathology materials? Endocr Pathol 1995;6:87-9.

30 Potten CS. What is an apoptotic index measuring? A commentary. Br f Cancer 1996;74:1743-8.

31 Levine EL, Renehan A, Gossiel R, Davidson SE, Roberts SA, Chadwick C, et al. Apoptosis, intrinsic radiosensitivity and prediction of radiotherapy response in cervical

32 Leoncini L, Del Vecchio MT, Megha T, Barbini P, Galieni P, Pileri S, et al. Correlations between apoptotic and proliferative indices in malignant non-Hodgkin's lymphomas. Am f Pathol 1993;142:755-63.

33 Aihara M, Truong LD, Dunn JK, Wheeler TM, Scardino 0 PT, Thompson TC. Frequency of apoptotic bodies positively correlates with Gleason grade in prostate cancer. positively correlates with Gleason grade in prostate cancer.

34 Todd D, Yang G, Brown RW, Cao J, D'Agati V, Thompson ir TS, et al. Apoptosis in renal cell carcinoma: detection by in $G$ situ end-labelling of fragmented DNA and correlation with $N$ other prognostic factors. Hum Pathol 1996;27:1012-17.

35 Lipponen PK, Aaltomaa S. Apoptosis in bladder cancer as 응 related to standard prognostic factors and prognosis. $7 \mathrm{~J}$ Pathol 1994;173:333-9.

36 Baserga R. Principles of molecular cell biology of cancer: the cell cycle. In: Devita VI Jr, Hellman S, Rosenberg SA, eds. Cancer. Principles and practice of oncology. 4th edn. Philadelphia: JB Lippincott, 1993:60-6.

37 Mc Gahon A, Bissonette R, Schmitt M, Cotter KM, Green DR, Cotter TG. BCR-ABL maintains resistance of chronic myelogenous leukemia cells to apoptotic cell death. Blood
1994;83:1179-87.

38 Clarke AR, Sphyris N, Harrison DJ. Apoptosis in vivo and in vitro: conflict or complementarity? Mol Med Today 1996;2: 189-91.

39 Hall PA, Meek D, Lane DP. p53-integrating the complexity [editorial]. $\mathcal{F}$ Pathol 1996;180:1-5.

40 Perego P, Giarola M, Righetti SC, Supino R, Caserini C, Delia $\mathrm{D}$, et al. Association between cisplatin resistance and mutation of $\mathrm{p} 53$ gene and reduced Bax expression in ovarian carcinoma cell systems. Cancer Res 1996;56:556-62.

41 Bracey TS, Miller JC, Preece A, Paraskeva C. $\gamma$-radiationinduced apoptosis in human colorectal adenoma and carcinoma cell lines can occur in the absence of wild type p53. Oncogene 1995;10:2391-6.

42 Forrester K, Lupold SE, Ott VL, Chay $\mathrm{CH}$, Band V, Wang $\mathrm{XW}$, et al. Effects of p53 mutants on wild type 3 p53-mediated transactivation are cell type dependent. Oncogene 1995;10:2103-11.

43 Hickman JA. Apoptosis induced by anticancer drugs. Cancer Metast Rev 1992;11:121-39.

44 Smets LA. Programmed cell death (apoptosis) and response to anti-cancer drugs. Anti-Cancer Drugs 1994;5:3-9.

45 Eliopoulos AG, Kerr DJ, Herod J, Hodgkins L, Krajewski S, O Reed JC, et al. The control of apoptosis and drug resistance in ovarian cancer: influence of $\mathrm{p} 53$ and bcl-2. Oncogene 1995;11:1217-28.

sons

